\title{
Experimental and Numerical Investigation of 2A16 Aluminum and Pure Copper Magnetic Assisted Dissimilar Laser Wire Feed Welding Brazing
}

\section{Zhengtian Wang ( $\square$ chickenlv4@163.com )}

Nanchang Hangkong University - Qianhu Campus: Nanchang Hangkong University

Shuyuan Jiang

Nanchang Hangkong University - Qianhu Campus: Nanchang Hangkong University

\section{Yiping Chen}

Nanchang Hangkong University - Qianhu Campus: Nanchang Hangkong University

Zhenyu Xiong

Nanchang Hangkong University - Qianhu Campus: Nanchang Hangkong University

Dean $\mathrm{Hu}$

Nanchang Hangkong University - Qianhu Campus: Nanchang Hangkong University

Donghai Cheng

Nanchang Hangkong University - Qianhu Campus: Nanchang Hangkong University

\section{Research Article}

Keywords: 2A16 aluminum, T2 copper, Numerical simulation, Magnetic field-assisted welding, Dissimilar Laser welding

Posted Date: September 3rd, 2021

DOI: https://doi.org/10.21203/rs.3.rs-854459/v1

License: (c) (1) This work is licensed under a Creative Commons Attribution 4.0 International License.

Read Full License 


\title{
Experimental and numerical investigation of $2 \mathrm{A16}$ aluminum
}

\section{and pure copper magnetic assisted dissimilar laser wire feed}

\section{welding brazing}

\author{
Zheng-tian WANG ${ }^{1}$, Shu-yuan JIANG ${ }^{1}$, Yi-ping CHEN ${ }^{1}$, Zhen-yu XIONG* 1, De-an HU ${ }^{1}$, \\ Dong-hai CHENG ${ }^{1}$
}

1. School of Aeronautical Manufacturing Engineering, Nanchang Hangkong University, Nanchang 330063, China

Corresponding author.

E-mail address: xzyww@163.com (Zhen-yu XIONG)

\begin{abstract}
:
Magnetic field assisted welding could suppress defects and improve weld bead properties obviously. In this paper, a full factorial experiment with coaxial magnetic field assisted welding was conducted to study the mechanism of the magnetic field on the dissimilar laser wire feed welding brazing profile of aluminum and copper. Furthermore, a three dimensional numerical simulation model was developed to reveal the influence of the magnetic field on the weld bead. It was found that with the magnetic flux density increase from $10 \mathrm{mT}$ to $50 \mathrm{mT}$, the properties of the weld bead were improved significantly, and the wetting angle decreased from $53^{\circ}$ to $26^{\circ}$, the main fluid flow direction of the weld bead changed in to horizontal direction. Meanwhile, EDS and XRD results showed that the main intermetallic compounds (IMC) of $\mathrm{Al}_{2} \mathrm{Cu}$ and $\mathrm{CuZn}$ composition changed to $\mathrm{Al}_{4.2} \mathrm{Cu}_{3.2} \mathrm{Zn}_{0.7}$ in welding beads. Computed and measured distortions illustrated good agreement in the fusion zone.
\end{abstract}

Keywords: 2A16 aluminum; T2 copper; Numerical simulation; Magnetic field-assisted welding; Dissimilar Laser welding

\section{Introduction}

With the increasing demands for high performance and light weight structure, the technological progress has motivated manufacturing innovations by use of multi-materials products[1-3]. Aluminum, with excellent resistance to corrosion, low cost and and density; and copper, with high thermal and electrical conductivity, both are widely used in industry. The 
production of the aluminum-copper $(\mathrm{Al} / \mathrm{Cu})$ hybrids would enable a solution for engineering to undergo reducing mass and cost, improving the multi-material properties[4-5]. But the preparation of $\mathrm{Al} / \mathrm{Cu}$ hybrid system is a signification challenge work due to their vast differences in their physic properties such as thermal conductivity, melting point, and expansion coefficient [6-7].

Up to now, many researchers pay much attention to welding methods, optimizing process parameters and etc to improve the performance of $\mathrm{Al} / \mathrm{Cu}$ joining component, such as ultrasonic spot welding[8-10], explosive welding[11-12], friction stir welding[13-16] and laser welding[17-21], that have been applied in various industrial production. But the formation of the representative brittle phase of (intermetallic compounds) IMC is inevitable, which causes a seriously degradation of weld properties and large melt point difference[22]. Recently, brazing fusion welding technology have been widely used in dissimilar metal welding due to its excellent controllability of heat and IMC's formation[23]. Previous researches have been demonstrated the advantage of brazing fusion welding in dissimilar metal welding with large difference of melt point [24-26].

The application of magnetic field in laser and arc welding with obviously effect in improving the quality of the welding bead due to its Hartman and thermoelectrical effect[27-28]. Wu, C et al[29] found that the external magnetic field can remarkably adjust the weld pool fluid flow field and decrease the momentum of the backward flowing molten jet, and the quality of the weld bead is remarkably improved. Avilov et al[30] verified that the surface tension cannot stop the gravity drop without the support from external magnetic field. Cao, L et al[31] built a hybrid methodology by combining radial basis function neural network (RBFNN) and genetic algorithm (GA) to solve the problem of the selection about appropriate processing parameters, and conducted the verification experiments to illustrate the effectiveness of the calculated optimal processing parameters. Results demonstrate that the processing parameters chosen by the model has significant improved the quality of the welding beat. Fan, L et al [31] investigated that the static magnetic field manifest a suppressing effect on the interdiffusion behavior of Fe-Fe50wt.\% $\mathrm{Si}$ diffusion couples, but there isn't observable difference of the diffusivity between parallel and perpendicular of the magnetic field direction.

In the mentioned above, the influence of the magnetic field have been concluded by experiments, but the influence mechanism of the magnetic on molten pool is extremely complicated. Furthermore, a more effective numerical model is necessary to investigated the melt pool dynamics under the influence of the magnetic field. Cao, L et al[32] created a three dimensional numerical model to reveal the mechanism of magnetic field by analyzing the characteristics of the molten pool. Their simulation results proved that the magnetic field can suppress both the lower to upper region and center to edge molten flows of the molten pool, which reduces the heat transfer from the tip of the keyhole to the molten pool surface and from the center to the boundary of the molten pool. Bachmann, M. et al[33] erected a three dimensional turbulent steady state numerical model for analyzing the effects of an alternating electromagnetic field on the complete penetration laser welding. Their simulation results signified that the sagging of molten metal caused by hydrostatic pressure could be reduced because an oscillating magnetic 
field would induce an eddy current in the molten pool. $\mathrm{Wu}, \mathrm{C}$ et al[34] established a three dimensional (3D) numerical simulation of the Ti-6Al-4V Gas Metal Argon Welding (GMAW) molten pool to investigate the molten pool's heat transfer and fluid flow behavior under a longitudinal magnetic field. The simulation results show that when the droplet enters the molten pool, the liquid metals on the surface symmetrically flow towards both sides of the molten pool from different angles. Furthermore, with the increase of the magnetic field strengthens, the temperature gradually decreases, and the fluid flow velocity increases continuously.

The purpose of this paper is to design a CFD model to predict distortions to investigate the influence of the magnetic field by analyzing the fusion zone of laser welding brazing of 2A16 aluminium $(\mathrm{Al})$ and $\mathrm{T} 2$ pure copper $(\mathrm{Cu})$.The experimental work includes:

1. Investigated the weldabiliy of the Al-Zn fillter wire under the influence of different magnetic field parameter by OM and SEM.

2. Characterization of the IMC's of the weld bead produced under different magnetic field parameters by EDS and XRD.

The modeling results includes:

1. A three dimensional numerical model of laser welding brazing of $2 \mathrm{~A} 16$ aluminium (Al) and $\mathrm{T} 2$ pure copper $(\mathrm{Cu})$ for prediction of temperature distribution and velocity distribution under different magnetic field parameters.

2. Comparing simulation results with experimental results.

\section{Material and experimental method}

\section{1 material}

The type 2A16 Aluminum plate and the type T2 pure copper is used for carrying out weld experiments. The dimension of the weldment is $120 \mathrm{~mm} \times 60 \mathrm{~mm} \times 2 \mathrm{~mm}$. The welding flux-core wire is $\mathrm{Zn}-10 \% \mathrm{Al}, \mathrm{Al}-\mathrm{Zn}$ alloy, which is selected as fillter wire to join the $\mathrm{Al}$ and $\mathrm{Cu}$ sheet. The chemical compositions of them are listed in Table 1.

Table1 The chemical compositions of the materials used

\begin{tabular}{lcccccc}
\hline Elements(wt\%) & $\mathrm{Al}$ & $\mathrm{Cu}$ & $\mathrm{Zn}$ & $\mathrm{Mn}$ & $\mathrm{Mg}$ & $\mathrm{Si}$ \\
\hline 2A16 & Bal & 6.0 & 0.1 & 0.4 & 0.05 & 0.3 \\
$\mathrm{~T} 2$ & - & Bal & 0.005 & - & - & - \\
\hline
\end{tabular}




\begin{tabular}{lllllll}
\hline Fillter metal & 10 & 0.05 & Bal & 0.02 & 0.09 & - \\
\hline
\end{tabular}

\section{2 experimental method}

Fig.1 shows the experimental platform. The laser beam was generate by a IPG YLS-6000CUT ytterbium laser, which was transmitted by a optical fiber and reaching to the welding head mounted on a KRC-30 6-axis robot. The radius of the laser spot was about $0.1 \mathrm{~mm}$, was skewed to the side of Al alloy plate with an offset value of $0.5 \mathrm{~mm}$. The pure argon $(35 \mathrm{~L} / \mathrm{min})$ is used as sheilding gas for performing laser butt welding. Before welding, all samples should be degreased by alcohol and dried. Especially, the aluminum oxide $\left(\mathrm{Al}_{2} \mathrm{O}_{3}\right)$ can induce inclusion, and adsorb moisture to cause formation of hydrogen porosity, so the aluminium plates surface were wiped with steel brush to remove oxides.

The coaxial magnetic field is generated by the magnetic head installed on the welding torch, and the structure of the magnetic head is showed on Fig.2(a). The excitation coil is fixed on the laser head to make sure the magnetic field is coaxial with the laser head, and the distance between the bottom of the excitation coil and the welding head kept at $5 \mathrm{~mm}$ during the welding process. The structure of the magnetic field device is showed on Fig.2(b).

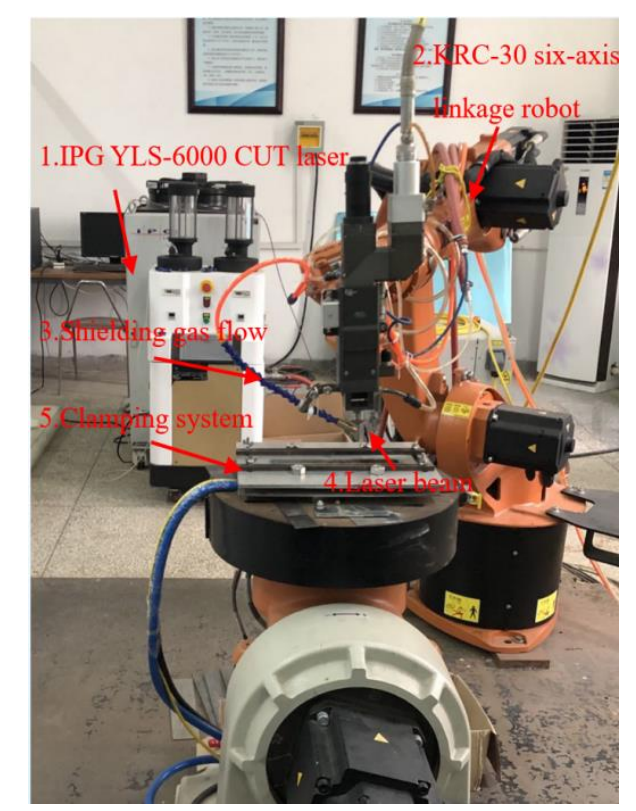

Fig.1 Schematic of the $\mathrm{Al} / \mathrm{Cu}$ butt welding 

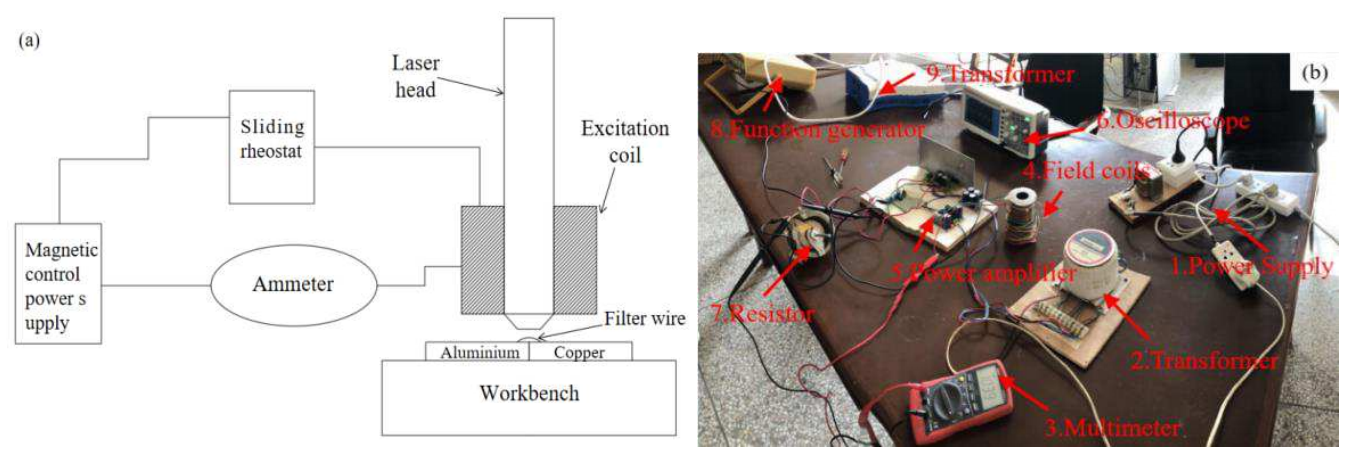

Fig.2 a Schematic of the magnetic head. $\quad$ b the magnetic field device:1 power supply; 2 transformer; 3 multimeter; 4 magnet exciting coil; 5 power amplifier; 6 oscilloscope; 7 resistor; 8 function generator; 9 transformer

After butt welding, the wire-cut EDM is used to cut the metallographic samples from the weldments, and the metallographic samples are ground by using 240\#, 400\#, 800\#, 1000\#, 1200\#, 1500\#, 2000\# grit $\mathrm{SiC}$ paper gradually, following polished with HYP-1 metallographic sample polishing machine, cleaned with the ultrasonic in alcohol and dried. Then the samples are immersed in the Keller's reagent $\left(5 \mathrm{~mL} \mathrm{HNO}_{3}+3 \mathrm{~mL} \mathrm{HCl}+2 \mathrm{~mL} \mathrm{HF}+19 \mathrm{~mL} \mathrm{H} 2 \mathrm{O}\right)$ for 15s, and observed by the OM(Axio Scope.A1) and the SEM (FEI Nova Nano SEM450) equipped with energy dispersive spectrometer system(EDS) for microstructure and element analysis respectively.

\section{Mathematical formulations}

To reveal the influence of the magnetic field in welding, a three dimensional transient numerical model is developed. The heat transfer, phase change, fluid flow, and the magnetic field are coupled in this model. The formulations are given in this section.

\subsection{Governing equation}

Since the the physics of magnetic field assisted laser welding are extremely complicated, it is inevitable to make several simplifications of the physical process without losing the most essential ones. The following simplifying assumptions made:

(1) The welding take place in a conduction mode (no keyhole formation) and the melt pool changes according to the melt pool convection.

(2) No chemical reaction in the welding pool.

(3) The effect of sheilding gas jet, nozzle's parameter on the weld bead are assumed negligible. 
(4) The mechanical behaviour during the welding process is of insignificant effect on the weld pool.

For the present study, commercially available CFD solver COMSOL Multiphysics 5.6 is utilized for simulating transient thermal and velocity fields. Fig.3(a), (b), (c) shows the geometry model and mesh model employed in CFD analysis. In this model, 322,289 hexahedral cells are chosen for mesh independence analysis. The minimum mesh size is $0.005 \mathrm{~m}$ in the fine zone utilized all along the welding direction, and beyond this zone, coarse mesh is used. The governing equations for mass, momentum, and energy conservation are as follows [27].

Mass conservation:

$$
\nabla \bullet(u)=0
$$

where $\mathrm{u}=(\mathrm{u}, \mathrm{v}, \mathrm{w})$ is the flow velocity vector.

Momentum conservation in X:

$$
\frac{\partial(\rho u)}{\partial t}+\nabla \cdot(\rho u u)=\nabla \cdot\left[-p+u\left(\left(\nabla u+(\nabla u)^{T}\right)-\frac{2}{3} \mu(\nabla \cdot u) I\right]+F\right.
$$

where $\rho$ is the mass density, $\mathrm{p}$ denotes the pressure, $\mu$ is the dynamic viscosity, and $\mathrm{F}$ is a source term which includes thermal buocancy, viscous force, and the Lorentz force. It is calculated as:

$$
\mathrm{F}=-\rho g \beta_{T}\left(T-T_{\text {melt }}\right)-Z_{\text {mush }} \frac{\left(1-f_{\text {liquid }}\right)^{2}}{f_{\text {liquid }}^{3}+c_{1}}+F_{\text {mag }}
$$

Where $\mathrm{g}, \beta_{\mathrm{T}}, \mathrm{T}$, and $\mathrm{T}_{\text {melt }}$ are the gravity acceleration, thermal expansion coefficient, local temperature, and melting temperature. The second term on the right hand of Eq. (3) denotes the dissipative force in the mushy zone of weld pool, $c_{1}$ is a very very small number $(0.00001)$ to avoid division by zero, $\left(Z_{\text {mush }}\right)$ is a default value of $10^{5}$ is used as mushy zone. The third term on the right hand of Eq. (3) is the lorentz force generated by the external magnetic field. The The liquid fraction $\mathrm{f}_{\text {liquid }}$ is calculated as:

$$
\left\{\begin{array}{cc}
0 & \mathrm{~T}<T_{S} \\
\frac{T-T_{s}}{T_{l}-T_{s}} & T_{s} \leq T \leq T_{l} \\
1 & T>T_{l}
\end{array}\right.
$$

Where $T_{1}$ and $T_{s}$ denote the liquidus and the solidus temperature of the material, respectively.

Energy conversation: 


$$
\frac{\partial}{\partial_{t}}(\rho H)+\nabla \cdot(\rho u H)=\nabla \cdot(\lambda \nabla T)
$$

where $\mathrm{H}, \lambda$, and are enthalpy, thermal conductivity.

$$
H=h_{r e f}+\int_{T_{r e f}}^{T} c_{p} d T+\Delta H
$$

where $\Delta \mathrm{H}, \mathrm{c}_{\mathrm{p}}, \mathrm{h}_{\mathrm{ref}}$ are latent heat, specific heat, and reference enthalpy.

(a)

(b)
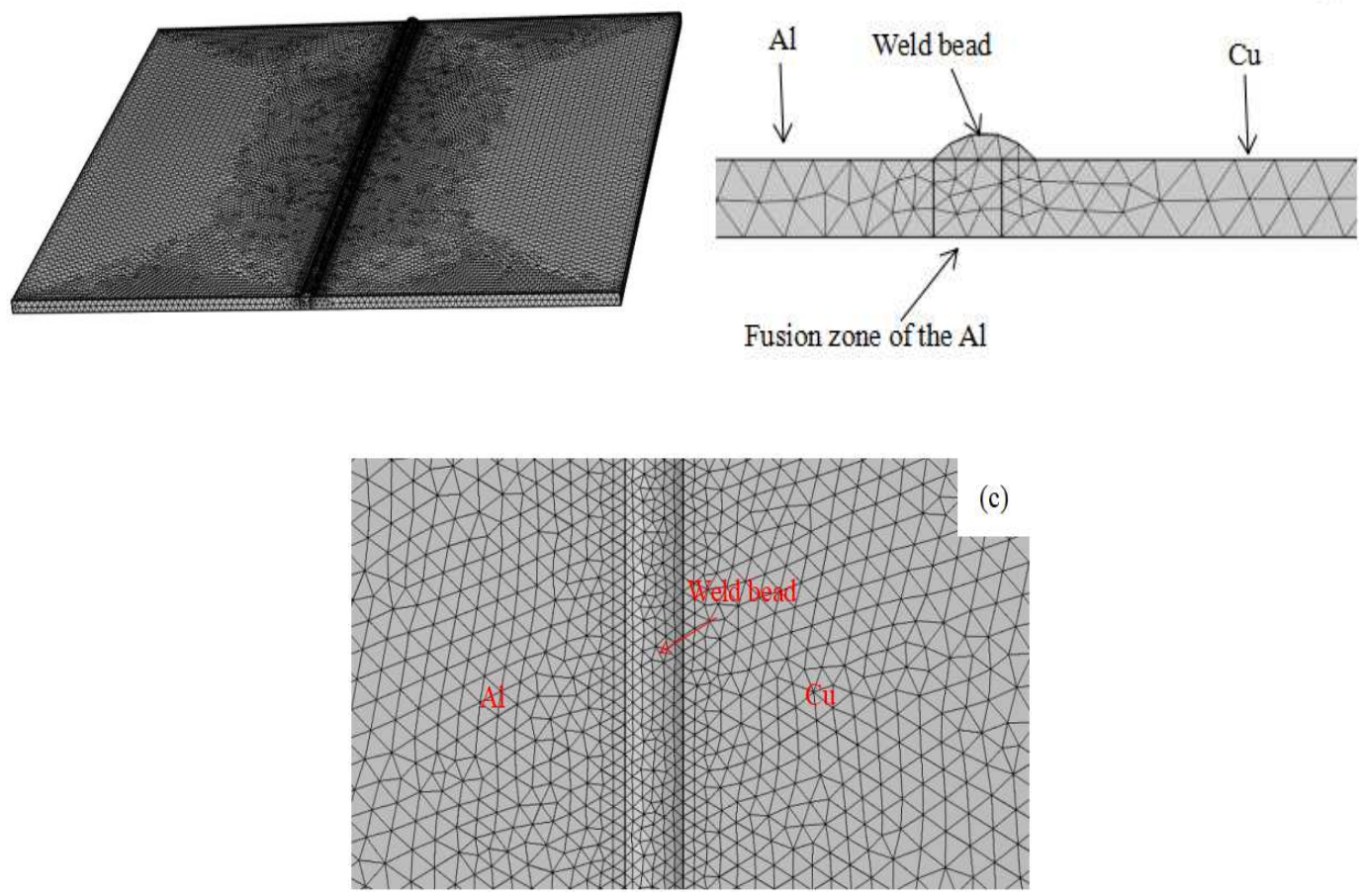

Fig.3 mesh model used for analysis (a): top side; (b): front side of the mesh model; (c): top side (magnified)

\subsection{Heat source model and magnetic field condition}

Latest researches have been devoted various type of heat source model in laser penetration welding[31, 35-38] . In this research, the heat source is based on Behúlová's model[38],

$$
Q(x, y, z)=\frac{9 \eta Q_{0} e^{3}}{\pi\left(e^{3}-1\right)} \frac{1}{\left(z_{e}-z_{i}\right)\left(r_{e}^{2}+r_{e} r_{i}+r_{i}^{2}\right)} \exp \frac{3\left(x^{2}+y^{2}\right)}{r_{0}^{2}(z)}
$$


where $\mathrm{Q}_{0}$ is the laser power input, $\eta$ is the efficiency, $\mathrm{r}_{\mathrm{e}}$ and $\mathrm{r}_{\mathrm{i}}$ are the surface radii in planes, $\mathrm{z}_{\mathrm{e}}$ and $\mathrm{z}_{\mathrm{i}}$ are the coordinate of the plate's top surface and bottom surface respectively, and $\mathrm{x}, \mathrm{y}, \mathrm{z}$ are the coordinates of the instant position of the heat source.

According to general Ohm's law, the movement of conducting particles in the magnetic field induces a current, its expression is:

$$
\mathrm{J}=k(E+u \times B)
$$

Where J, k, E, B are current density, electric conductivity, electric field, and magnetic flux density. For a steady magnetic field without external electric current source in this zone, the current electrical density calculated as:

$$
\mathrm{J}=k(u \times B)
$$

Then, the Lorentz force can be calculated as

$$
\mathrm{F}_{\text {mag }}=J \times B
$$

\section{Experimental result and analysis}

Fig.4(a) (f) is the influence of magnetic field strength on the weld section morphology under same laser welding parameter. As can be seen from Fig.4(a) (e), when the magnetic field increases with reference flux density from $10 \mathrm{mT}$ to $50 \mathrm{mT}$, the wetting angle gradually decreases from $53^{\circ}$ to $47^{\circ}, 37^{\circ}, 32^{\circ}$ and finally $26^{\circ}$, indicating that the wetting ability of $\mathrm{Zn}$-Al wire gradually increases with the increase of magnetic field intensity. Due to the coaxial longitudinal magnetic field is applied, the spread of the liquid metal on the molten pool surface to the copper base metal will be accelerated by the electromagnetic stirring action during the welding process, which is conducive to the diffusion of the liquid metal on the molten pool surface to the copper base metal.
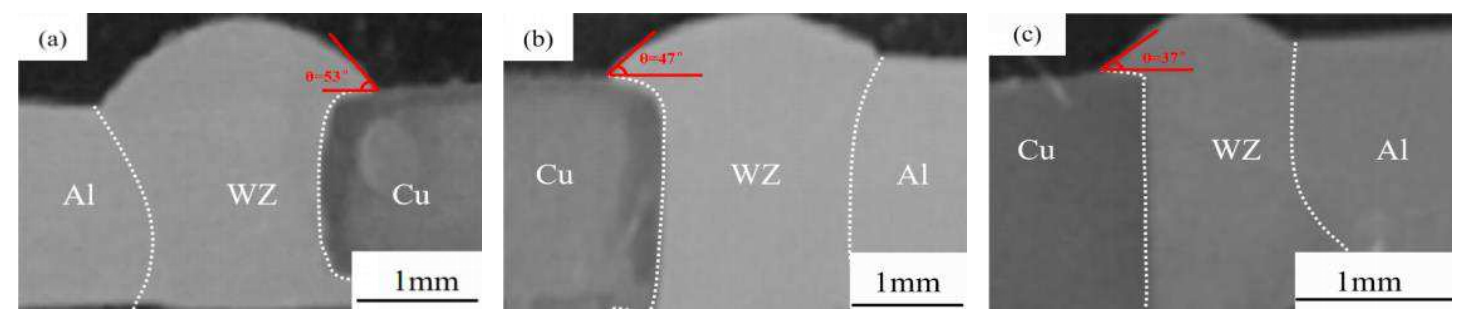

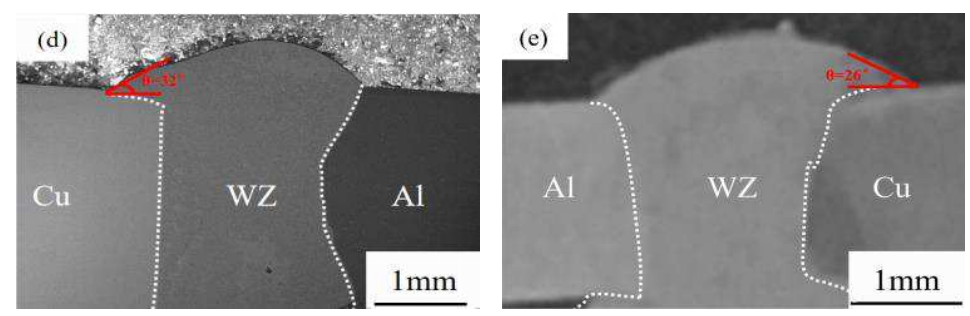

Fig4. the influence of the wetting angle in different reference flux density: (a) $B=10 \mathrm{mT}$; (b)

$$
\mathrm{B}=20 \mathrm{mT} \text {;(c) } \mathrm{B}=30 \mathrm{mT} \text {;(d) } \mathrm{B}=40 \mathrm{mT} \text {;(e) } \mathrm{B}=50 \mathrm{mT}
$$

Fig.5 (a), (c) and (e) respectively show the copper side brazing zone of the joint under different flux density in $10 \mathrm{mT}, 30 \mathrm{mT}, 50 \mathrm{mT}$. The thickness of IMC layer is measured as follows:3.85 $\mu \mathrm{m}, 5.0 \mu \mathrm{m}, 8.97 \mu \mathrm{m}$, which means the average thickness of IMC layer increases with the increase of magnetic field intensity. Fig.5 (b), (d) and (f) show the magnified images of their corresponding brazing zones on the copper side respectively. EDS analysis is shown in Table 2, and the XRD results showed in Fig.6. According to the EDS results, when $B=10$ and $B=30 \mathrm{mT}$, the ratio of $\mathrm{Cu}$ and $\mathrm{Zn}$ atoms at point 1 is 1:1, and the ratio of $\mathrm{Al}$ and $\mathrm{Cu}$ atoms at point 3 is 2:1, and the IMC layer is characterized composed of $\mathrm{CuZn}$ and $\mathrm{Al}_{2} \mathrm{Cu}$ compounds, but the growth trend of $\mathrm{Al}_{2} \mathrm{Cu}$ morphology along the weld zone is becoming obviously.

When the magnetic field intensity increases to $\mathrm{B}=50 \mathrm{mT}$, IMC layer II is obviously composed of two parts, one part is layered next to the I layer, the other part is dendritic growing towards the weld zone, these dendritic structures are long, thin and abundance. According to the atomic ratio of $\mathrm{Al}, \mathrm{Cu}$ and $\mathrm{Zn}$ at point. 2 and point. 3 combined with EDS and XRD patterns, they are all $\mathrm{Al}_{4.2} \mathrm{Cu}_{3.2} \mathrm{Zn}_{0.7}$ ternary compounds. With the continuous increase of magnetic field strength, the electromagnetic stirring effect in the molten pool is enhanced, the heat on the molten pool surface is distributed more evenly, meanwhile the period of molten pool at high temperature is reduced, so that the formed $\mathrm{CuZn}$ is promoted to transform into $\mathrm{Al}_{4.2} \mathrm{Cu}_{3.2} \mathrm{Zn}_{0.7}$ compound. Besides, due to the charged fluid in the molten pool drives the liquid metal to rotate in the same direction, the flow rate of the molten pool increases to scour the copper interface, making more $\mathrm{Cu}$ diffused to the molten pool, and $\mathrm{Al}_{4.2} \mathrm{Cu}_{3.2} \mathrm{Zn}_{0.7}$ compound precipitates after the molten pool solidification. The existence of slender dendritic $\mathrm{Al}_{4.2} \mathrm{Cu}_{3.2} \mathrm{Zn}_{0.7}$ ternary compound in the weld and its special morphology distribution gradually inhibited the growth of $\mathrm{Al}_{2} \mathrm{Cu}$. when the magnetic density increased in to $50 \mathrm{mT}$, where IMC is composed of $\mathrm{CuZn}$ in layer I and $\mathrm{Al}_{4.2} \mathrm{Cu}_{3.2} \mathrm{Zn}_{0.7}$ in layer II. Therefore, a part of layer II is striplike is next to layer I, and the other part is elongated dendritic along the weld, in which the $\mathrm{Al}_{2} \mathrm{Cu}$ compound is decreased obviously. 

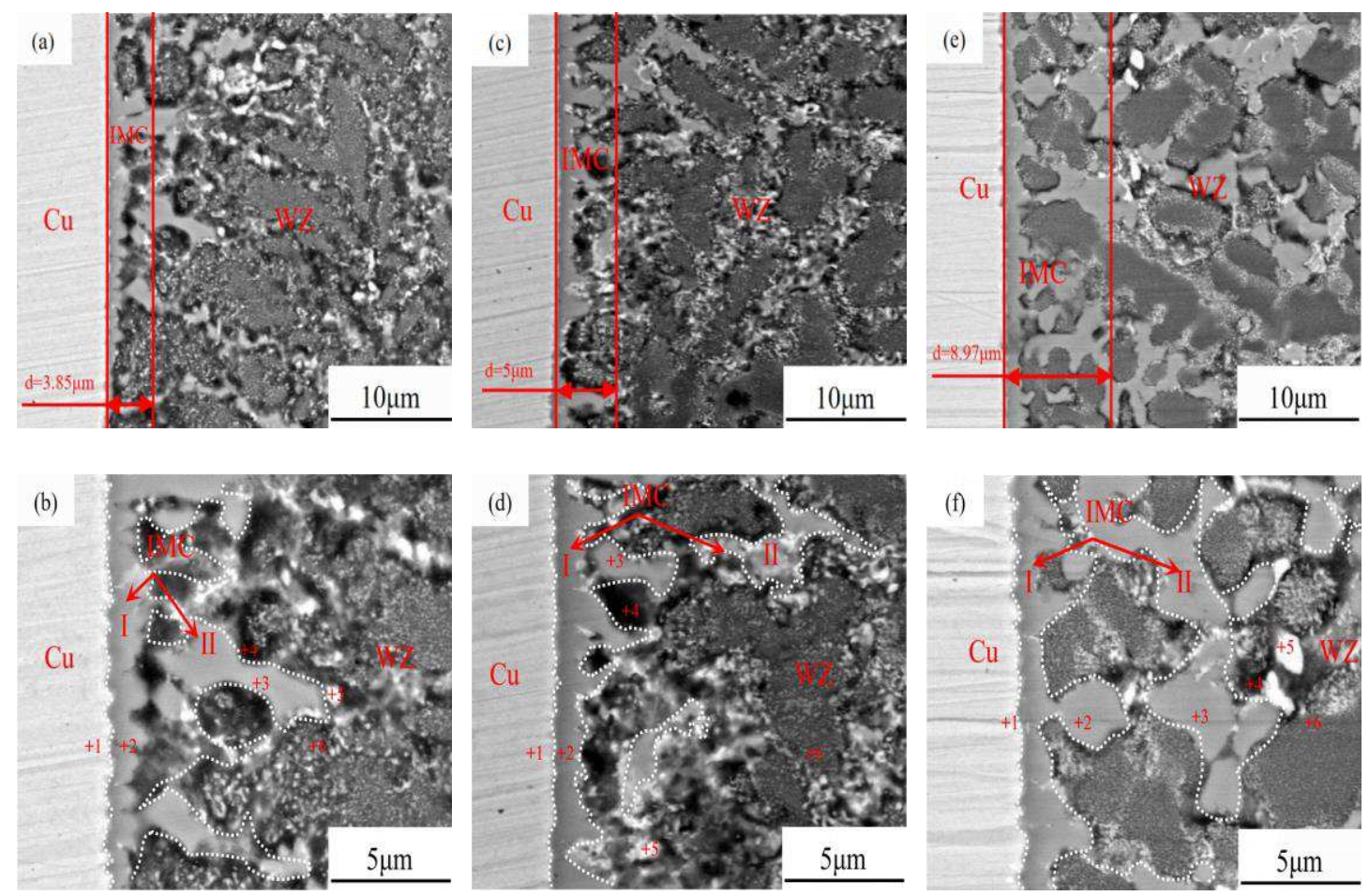

Fig5. Microstructure images of the $\mathrm{Al} / \mathrm{Cu}$ welding brazing joint in different flux density: a, b $\quad B=10 \mathrm{mT}$. c, d $\quad B=30 \mathrm{mT}$. e, f $\quad B=50 \mathrm{mT}$.
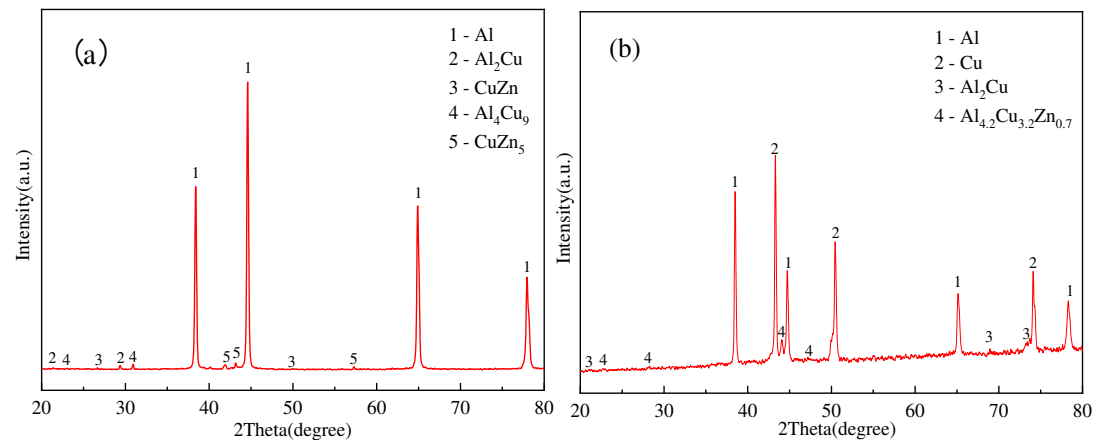

Fig6. XRD analyse results in different magnetic flux density : (a): $B=10 \mathrm{mT}$; (b): $\mathrm{B}=50 \mathrm{mT}$

Table2 EDS analysis result of weld joint (atom $\%$ )

\begin{tabular}{cccccccc}
\hline Magnetic density: & Point & 1 & 2 & 3 & 4 & 5 & 6 \\
\hline \multirow{2}{*}{$\mathrm{B}=10 \mathrm{mT}$} & $\mathrm{Al}$ & 0 & 3.63 & 67.78 & 78.41 & 20.12 & 47.67 \\
& $\mathrm{Cu}$ & 100 & 51.62 & 26.77 & 0.65 & 3.32 & 5.39 \\
\multirow{2}{*}{ Possible phase } & $\mathrm{Zn}$ & 0 & 44.75 & 5.35 & 20.93 & 76.56 & 46.94 \\
& & $\mathbf{C u}$ & $\mathbf{C u Z n}$ & $\mathbf{A \mathbf { l } _ { 2 } \mathbf { C u }}$ & $\boldsymbol{\alpha}$-Al & $\boldsymbol{\beta}-\mathbf{Z n}$ & $\boldsymbol{\alpha}-\mathbf{A l}+\boldsymbol{\beta}-\mathbf{Z n}$ \\
$\mathrm{B}=30 \mathrm{mT}$ & $\mathrm{Al}$ & 0 & 8.73 & 66.56 & 79.25 & 15.73 & 48.20 \\
& $\mathrm{Cu}$ & 100 & 49.98 & 26.75 & 8.07 & 3.56 & 5.42 \\
Possible phase & $\mathrm{Zn}$ & 0 & 41.29 & 6.69 & 12.68 & 80.71 & 46.38 \\
& & $\mathbf{C u}$ & $\mathbf{C u Z n}$ & $\mathbf{A l} \mathbf{2} \mathbf{C u}$ & $\boldsymbol{\alpha}$-Al & $\boldsymbol{\beta}-\mathbf{Z n}$ & $\boldsymbol{\alpha}-\mathbf{A l}+\boldsymbol{\beta}-\mathbf{Z n}$ \\
$\mathrm{B}=50 \mathrm{mT}$ & $\mathrm{Al}$ & 7.78 & 56.68 & 53.21 & 69.09 & 18.25 & 56.15 \\
& $\mathrm{Cu}$ & 92.22 & 32.64 & 32.10 & 28.94 & 12.93 & 2.98 \\
\hline
\end{tabular}




\begin{tabular}{|c|c|c|c|c|c|c|c|}
\hline & $\mathrm{Zn}$ & 0 & 10.68 & 12.73 & 1.96 & 68.82 & 40.87 \\
\hline Possible phase & & $\mathbf{C u}$ & $\mathbf{A l}_{4.2} \mathbf{C u}_{3.2} \mathbf{Z n}_{0.7}$ & $\mathrm{Al}_{4.2} \mathrm{Cu}_{3.2} \mathrm{Zn}_{0}$ & $\mathrm{Al}_{2} \mathbf{C u}$ & $\beta-Z n$ & $\alpha-\mathbf{A l}+\boldsymbol{\beta}-\mathbf{Z n}$ \\
\hline
\end{tabular}

\section{Simulation result and disscution}

The simulation influence of the steady magnetic field in the molten's flow and weld pool is based on the fluid flow simulation carried out by varying the magnetic flux density in $0 \mathrm{mT}, 30 \mathrm{mT}$ and $50 \mathrm{mT}$ for a welding parameter in $2200 \mathrm{w}, 0.12 \mathrm{~m} / \mathrm{s}$; defocus distance in $+10 \mathrm{~mm}$. The material properties of 2A16, T2 copper and the fillter wire used in analysis are presented in tabel 3. 2A16 and fillter wire's material properties are calculated by a commercial thermal-analysis software Jmatpro, and T2 copper's material's properties are adopted according to previous researches [39-41]. The predicted temperature and velocity profiles of the weld pool for magnetic field assisted welding brazing are presented and discussed.

Table 3 Physical properties of substrate

\begin{tabular}{|c|c|c|c|c|}
\hline $\begin{array}{l}\text { Physical } \\
\text { properties }\end{array}$ & Symbol [unit] & $\begin{array}{l}\text { 2A16 } \\
\text { aluminum }\end{array}$ & T2 copper & Fillter wire \\
\hline Melting point & $\operatorname{Tm}[\mathrm{K}]$ & 933 & 1356.15 & 798.15 \\
\hline Mass density & $\rho[\mathrm{kg} / \mathrm{m} 3]$ & 2700 & 8970 & 5560 \\
\hline $\begin{array}{l}\text { Thermal } \\
\text { conductivity }\end{array}$ & $\lambda[\mathrm{W} / \mathrm{m} * \mathrm{~K}]$ & 175.2 & 416.3 & 67.98 \\
\hline $\begin{array}{l}\text { Dynamics } \\
\text { viscosity }\end{array}$ & $\mu\left[\mathrm{Pa}^{*} \mathrm{~s}\right]$ & $1.54 * 10^{-3}$ & $3.78 * 10^{-3}$ & $1.38 * 10^{-3}$ \\
\hline Specific heat & $\mathrm{Cp}[\mathrm{J} /(\mathrm{kg} * \mathrm{~K})]$ & 1176.52 & 572.2 & 525.6 \\
\hline Melting latent & $\mathrm{L}[\mathrm{kJ} / \mathrm{kg}]$ & 385.3 & 188.5 & 147.9 \\
\hline $\begin{array}{l}\text { Marangoni } \\
\text { coefficient }\end{array}$ & $\frac{\sigma_{\gamma}}{\sigma_{\mathrm{T}}}\left[N /\left(m^{*} K\right)\right]$ & $-0.6 * 10^{-4}$ & $-1.56^{*} 10^{-4}$ & $-0.43 * 10^{-4}$ \\
\hline
\end{tabular}




\begin{tabular}{lllll}
\hline $\begin{array}{l}\text { Electrical } \\
\text { conductivity }\end{array}$ & $\sigma[\mathrm{S} / \mathrm{m}]$ & $3.93 * 10^{6}$ & $1.43 * 10^{7}$ & $2.57 * 10^{6}$ \\
\hline
\end{tabular}

\subsection{Temperature field and velocity field simulation}

For comparison and validation, a reference case without the magnetic field was simulated. Fig. 7a-d shows the velocity field and temperature field of the molten pool without magnetic field, where typical flow pattern that liquid metal flows from the center towards the edge of the molten pool, the maximum weld surface temperature observed is $1393 \mathrm{~K}$ as shown in Fig. 4a, and the maximum fluid flow velocity in $\mathrm{x}$-axis direction achieved is about $0.07 \mathrm{~m} / \mathrm{s}$ at the top surface of the weld bead.

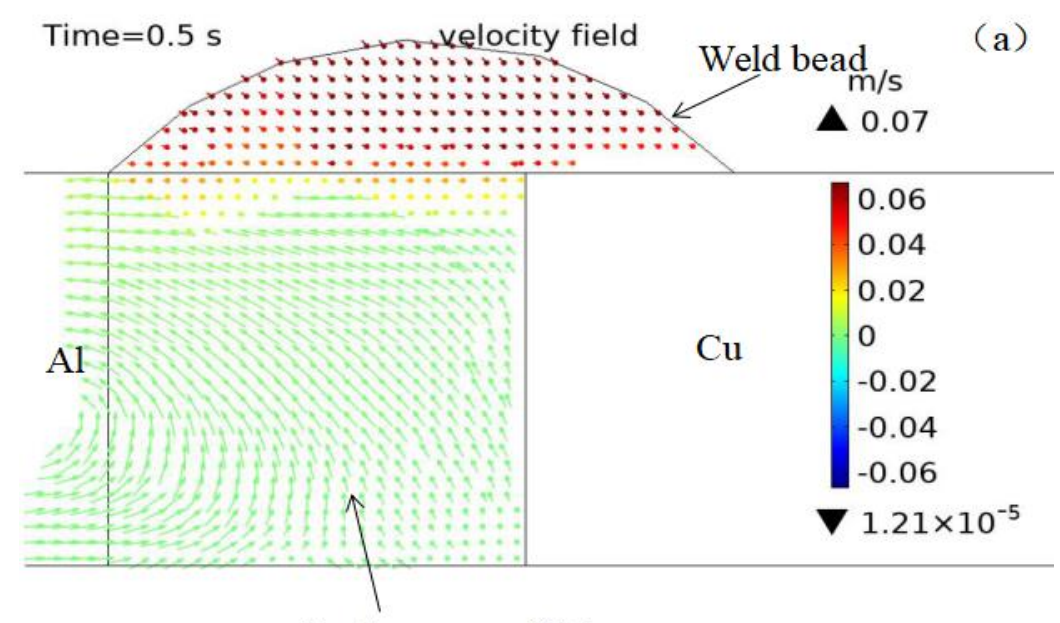

Fusion zone of $\mathrm{Al}$
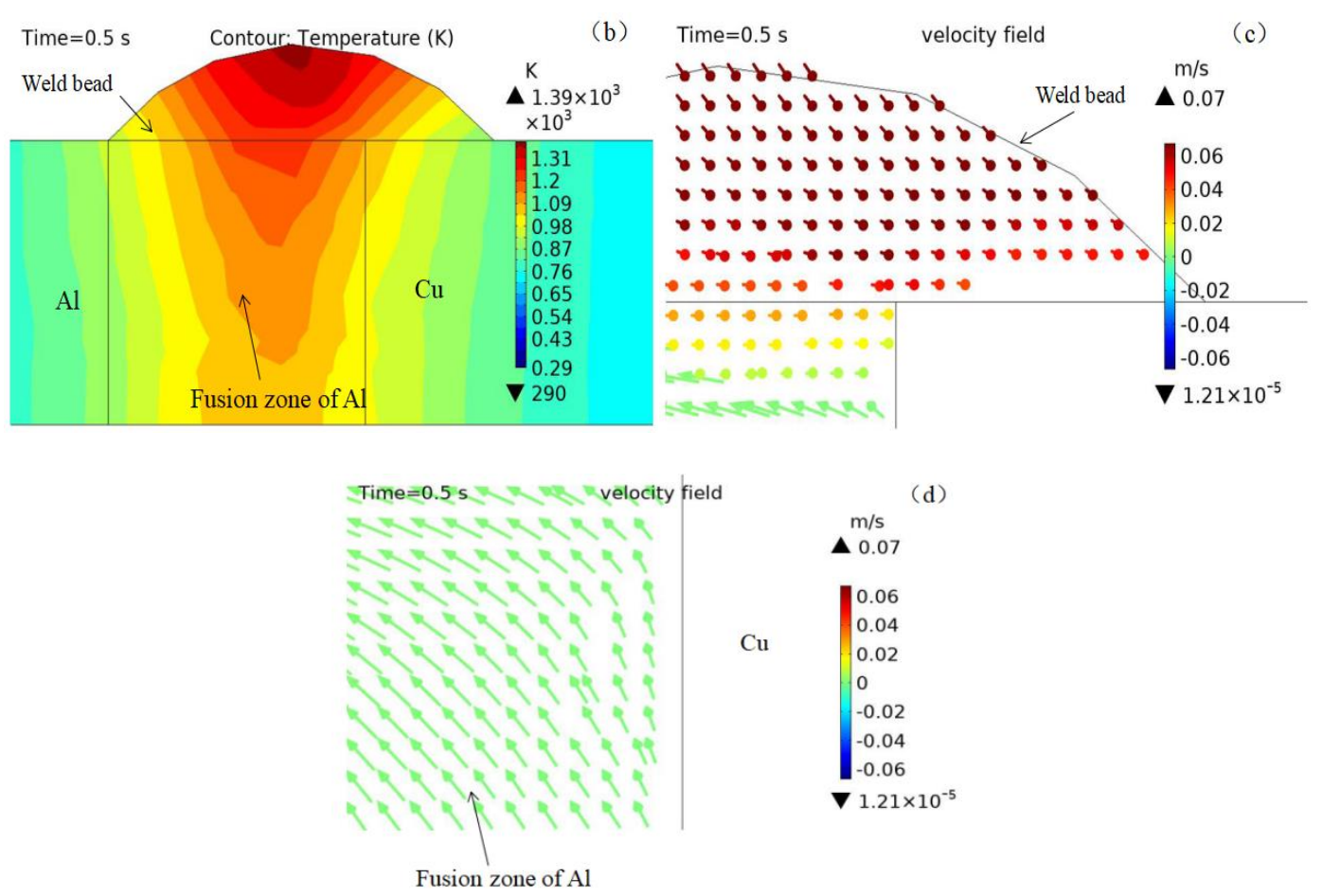
Fig7. Temperature contour and velocity magnitude without magnetic field along the xz direction: (a): velocity field; (b): temperature field; (c): velocity field at weld bead (magnified); (d): velocity field at barrier between fusion zone of the aluminum and copper (magnified)

Fig. 8a-d demonstrates the temperature field and velocity field of the moltem pool under magnetic field in $30 \mathrm{mT}$. Fig. $8 \mathrm{~b}$ shows that the isothermal narrowed obviously compared with the sample without magnetic field assisted. The liquid flows upwards close to the Al's melten pool's barrier and downwards along the edge of the molten pool. With the magnetic field assisted, the Lorentz force changed the fluid flow's direction, the velocity field at the weld bead changed obviously, the maximum fluid flow velocity increased in to $0.084 \mathrm{~m} / \mathrm{s}$ at top surface of the weld bead. When the magnetic flux density increased in to $50 \mathrm{mT}$. The maximum fluid flow velocity and the flow pattern hasn't change obviously compared to the sample with magnetic field in 30mT. For quantitatively study of the influence of the magnetic field on the flow velocity, the velocities in horizontal direction in the point showed in Fig.9a at the same time are extracted, it increases as the magnetic flux density grows, Fig. 9 (b). Combined with the experimental results of wetting angle decreased as the magnetic flux density increased, a mixed melten pool formed by the welding wire and and aluminum even with the a little copper which scoured from copper by the enhanced fluid flow, that causes its surface tension gradient is lower than the pure metal's, is verified by EDS and XRD results. With magnetic field assisted, a volume force produced by lorentz force changed the main direction of the fluid flow to the horizontal direction and enlarged the velocity, which maybe the main factor to cause the decrease of the wetting angle.

Furthermore, by comparing fig8 (d) and fig9 (d), it can be found that the lorentz force cause a stirring effect on molten pool and accelerate the erosion of the copper interface, while the temperature gradient and the time of high temperature is decreased. With the magnetic flux density increased into $50 \mathrm{mT}$, which enhanced flow strring and allowing more $\mathrm{Cu}$ spread to the molten pool, combing the experimental results of EDS and XRD, the main IMCs' composition of $\mathrm{Al}_{2} \mathrm{Cu}$ and $\mathrm{CuZn}$ is changed in to the $\mathrm{Al}_{4.2} \mathrm{Cu}_{3.2} \mathrm{Zn}_{0.7}$ ternary compounds.

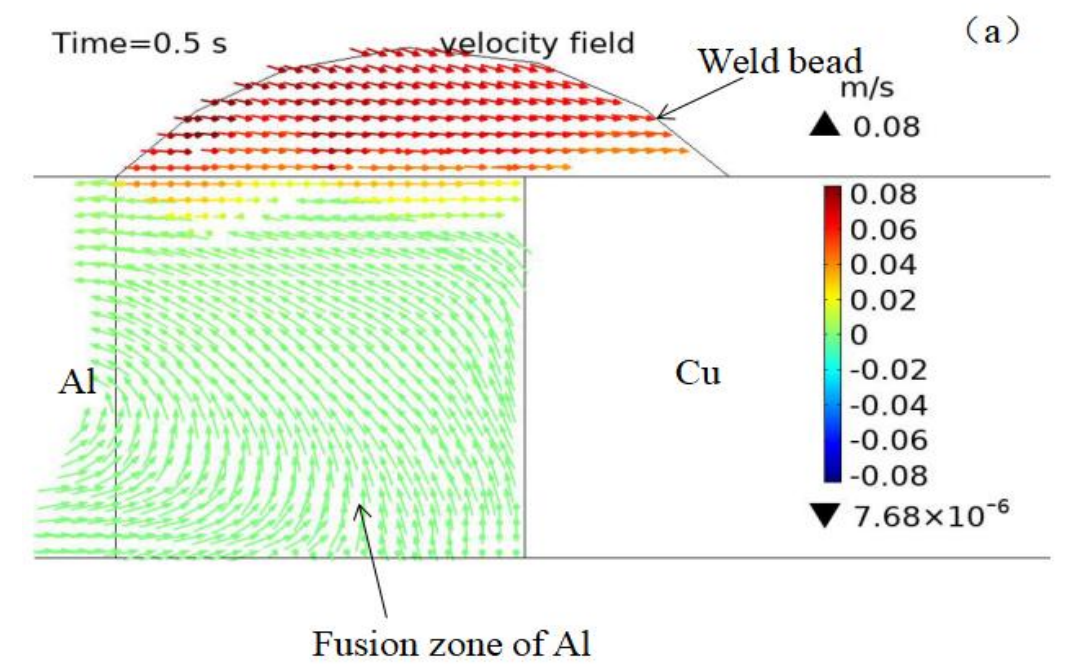



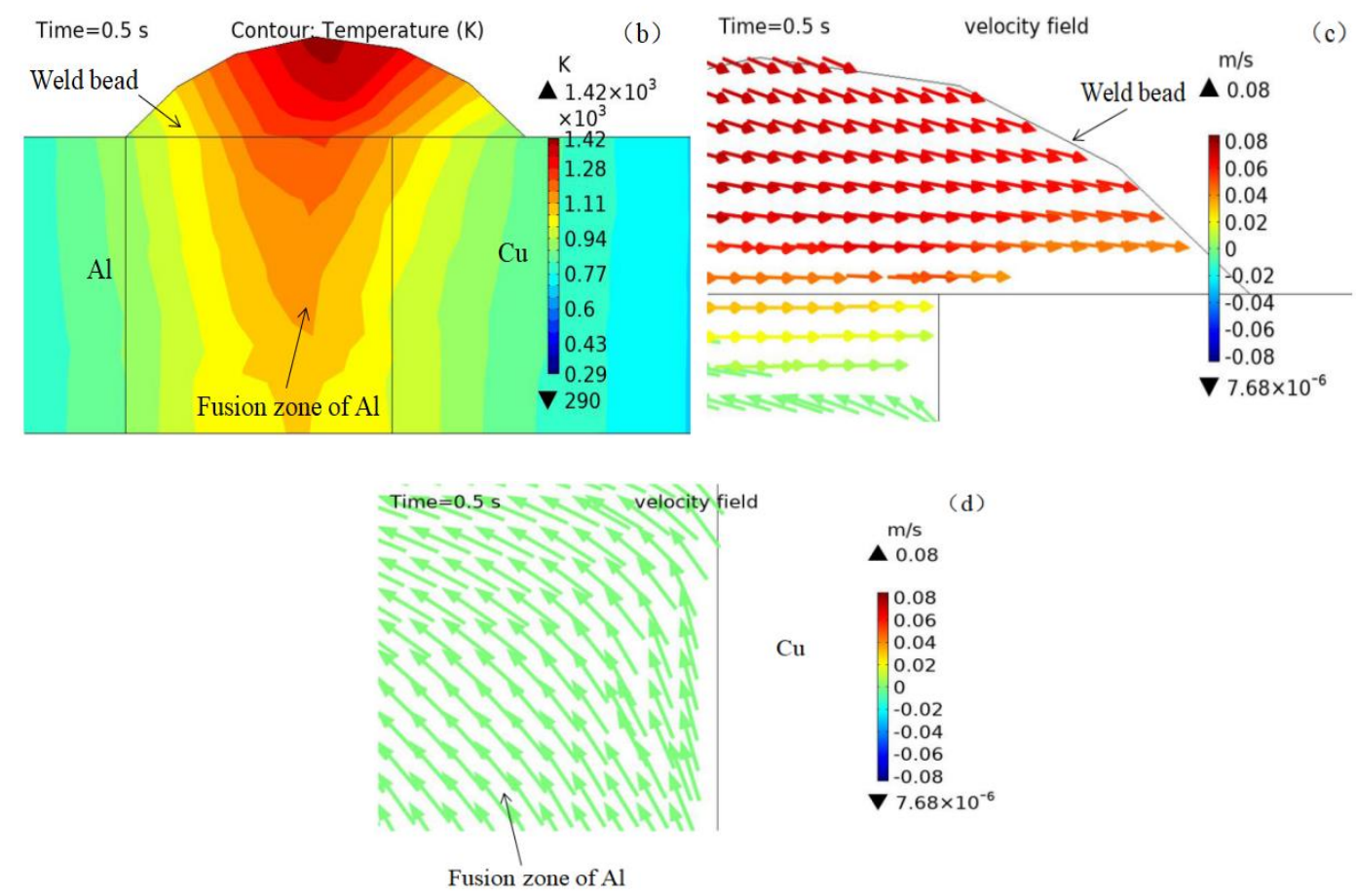

Fig8. Temperature contour and velocity magnitude with $30 \mathrm{mT}$ magnetic field along the $\mathrm{xz}$ direction: (a): velocity field; (b): temperature field; (c): velocity field at weld bead (magnified); (d): velocity field at barrier between fusion zone of the aluminum and copper (magnified)
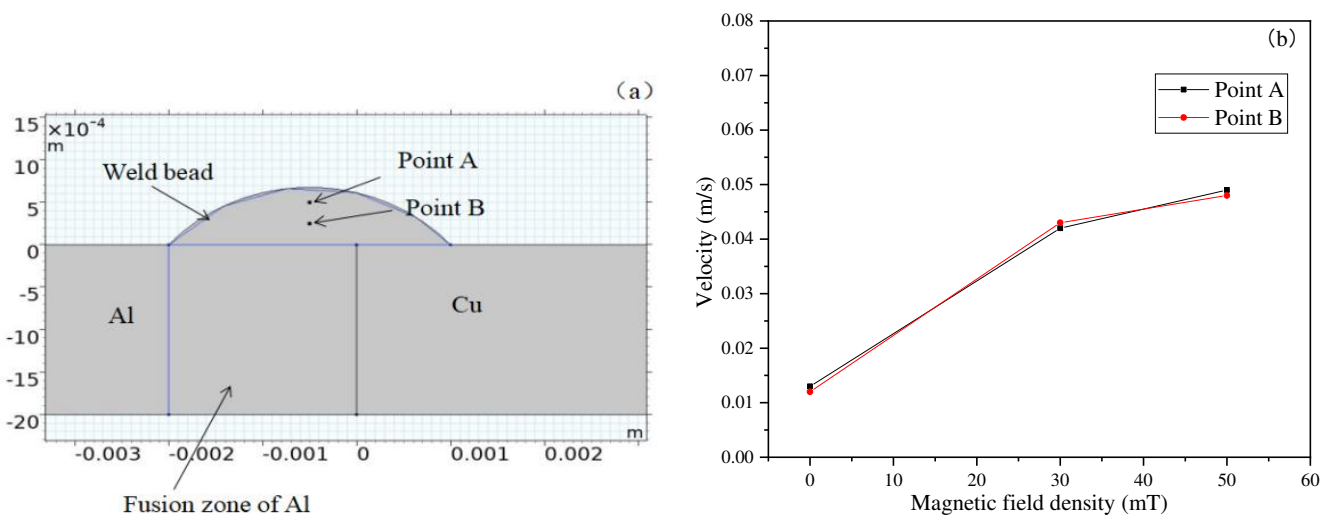

Fig9. Influence of magnetic field on the flow velocity on the test point in weld bead's molten pool:

(a): Test point location; (b)distribution of the magnitude of the flow velocity under different magnetic field

\subsection{Comparison between simulation and experimental results}

To validate the numerical model, with the assumption that the liquid metal in the molten pool is assumed as incompressible, laminar, solid-liquid two-phase Newtonian flow and the influence of the wettability of the fillter wire under different magnetic field intensity wasn't considered, the cross-section shapes of the weld beads are compared. Fig.10 demonstrates that the simulation results is in good agreement with the experiment results in terms of the width, but there are 
differences between the simulation and experimental results in the geometry shape and the wetting angle of of the weld bead. The reasons are the difficulty of acquiring real physical properties of the material at high temperature. It is a challenge for numerical simulation.
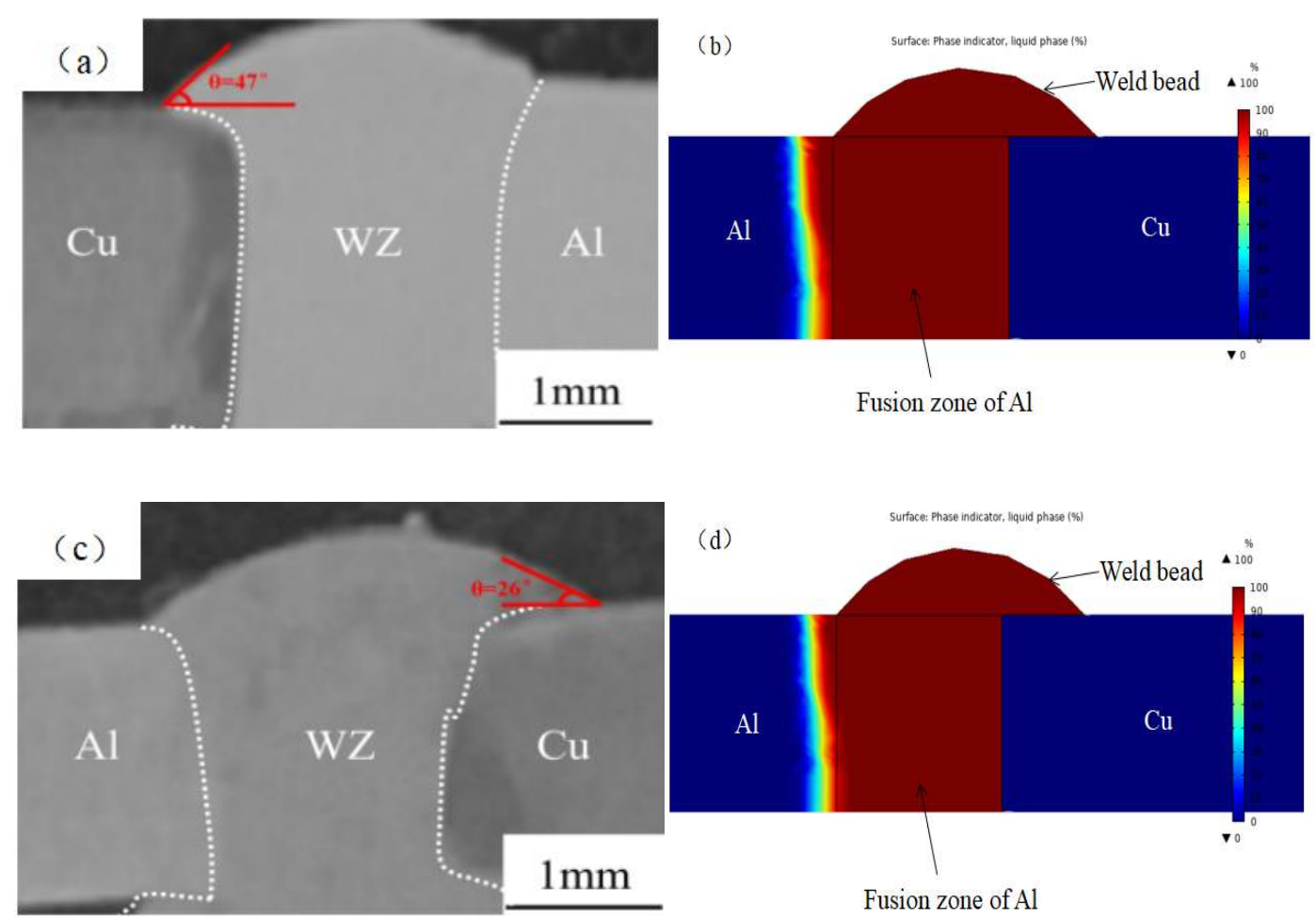

Fig.10 Comparison of cross-sections of the weld bead under the effects of a magnetic field: (a): the experimental result without a magnetic field; (b): the simulation result without a magnetic field; (c): the experimental result with magnetic flux density of $50 \mathrm{mT}$; (d) the simulation result with magnetic flux density of $50 \mathrm{mT}$

\section{Conclusion}

Experimental and numerical simulation research has been conducted to investigate the influence of the magnetic field on the weld profile of aluminum and copper dissimilar laser wire feed welding brazing from the molten pool flow and heat transfer. The major conclusions are listed below:

1. A full factorial experiment was conducted. The results show that the wetting angle gradually decreases as the magnetic flux density increases.

2. The average thickness of IMC layer increases with the increase of magnetic the coaxial field intensity. When the magnetic flux density increased to $50 \mathrm{mT}$, the main composition of $\mathrm{Al}_{2} \mathrm{Cu}$ and $\mathrm{CuZn}$ changed in to the $\mathrm{Al}_{4.2} \mathrm{Cu}_{3.2} \mathrm{Zn}_{0.7}$ ternary compounds.

3. The simulation result is in good agreement with the experiment result in terms of the 
weld width. With the coaxial magnetic field assisted, the main melt fluid flow direction of the weld bead changed in to horizonal direction. The flow velocity in horizontal direction increases as the magnetic flux density grows.

4. The coaxial magnetic field impacts the melting fluid convection, increases the width of weld bead, improves wettability, changes the thickness of IMC layer and IMC compounds, which demonstrates the magnetic field, surface tension, gravity, thermal convection, Lorenz force, constitute a hierarchy structure to control the melting pool and solidification of the welding, and finally control the characteristics of welding beads.

\section{Declaration}

Funding: This research was supported by the National Natural Science Foundation of China (grant number 51865034)

Conflicts of interest/Competing interests: Not applicable

Availability of data and material: Not applicable

Code availability : Not applicable

Ethics approval : Not applicable

Consent to participate : Not applicable

Consent for publication : Not applicable

Authors' contributions : Not applicable

\section{Reference}

[1] Cheepu, M. , \& Susila, P. . (2020). Growth rate of intermetallics in aluminum to copper dissimilar welding. Transactions of the Indian Institute of Metals, 73(6):1509-1514.

https://doi.org/10.1007/s12666-020-01905-z

[2] Pratyusha, M. , Ramana, P. V. , \& Prasanthi, G. . (2020). Evaluation of tensile strength of dissimilar metal pure aluminium and pure copper friction welds. Materials Today: Proceedings, 38(5):2271-2274. https://doi.org/10.1016/j.matpr.2020.06.385 
[3] DebRoy T, Bhadeshia HKDH. .(2010). Friction stir welding of dissimilar alloys -a perspective. Sci Technol Weld Joining ;15:266-70. https://doi.org/10.1179/174329310X12726496072400

[4] Galva O, I. , Oliveira, J. C. , Loureiro, A. , \& Rodrigues, D. M. . (2012). Formation and distribution of brittle structures in friction stir welding of aluminium and copper: influence of shoulder geometry. Intermetallics, 22(none), 122-128.

https://doi.org/10.1016/j.intermet.2011.10.014

[5] Hofmann K, Holzer M, Hugger F, Roth S, Schmidt M. Reliable copper and aluminum connections for high power applications in electromobility. Phys Procedia 2014;56:601-9. https://doi.org/10.1016/j.phpro.2014.08.048

[6] Muhammad, N. A. , \& Wu, C. S. . (2019). Ultrasonic vibration assisted friction stir welding of aluminium alloy and pure copper. Journal of Manufacturing Processes, 39(MAR.), 114-127.https://doi.org/10.1016/j.jmapro.2019.02.011

[7] Lipowsky H, Arpaci E. Copper in the Automotive Industry. 2007.

https://doi.org/10.1002/9783527611652.

[8] Satpathy, M. P. , Mishra, S. B. , \& Sahoo, S. K. . (2018). Ultrasonic spot welding of aluminum-copper dissimilar metals: a study on joint strength by experimentation and machine learning techniques. Journal of Manufacturing Processes, 33(JUN.), 96-110.https://doi.org/10.1016/j.jmapro.2018.04.020

[9] Shen, J. , Suhuddin, U. , Cardillo, M. , \& Santos, J. D. . (2014). Eutectic structures in friction spot welding joint of aluminum alloy to copper. Applied Physics Letters, 104(19),

541-550.https://doi.org/10.1063/1.4876238

[10] Feng, M. N. , Xie, Y. , CF Zhao, \& Luo, Z. . (2018). Microstructure and mechanical performance of ultrasonic spot welded open-cell cu foam/al joint. Journal of Manufacturing Processes, 33(JUN.), 86-95. https://doi.org/10.1016/j.jmapro.2018.04.022

[11] Li, Y. , Dong, Y. , Fu, Y. , \& Li, X. . (2019). Interfacial structure and mechanical properties of the explosive welded $t 2$ copper/2024 aluminium alloy joint. Cailiao Kexue yu Gongyi/Material Science and Technology, 27(1), 47-52. http://dx.doi.org/10.11951/j.issn.1005-0299.20170295

[12] Mousavi, S. , Al-Hassani, S. , \& Atkins, A. G. . (2008). Bond strength of explosively welded specimens. Materials \& Design, 29(7), 1334-1352. https://doi.org/10.1016/j.matdes.2007.06.010

[13] Chowdhury, I. D. , Sengupta, K. , Singh, D. K. , Maji, K. K. , \& Mondal, A. K. . (2020). Investigation of mechanical properties of dissimilar joint of 6063 aluminium and c26000 copper alloy by friction stir welding. Materials Today: Proceedings.44(6),4039-4047.

https://doi.org/10.1016/j.matpr.2020.10.219

[14] Chularis, A. A. , Rzaev, R. A. , \& Syndetov, M. K. . (2021). Friction stir welding of aluminium and copper alloys. Welding International(8), 1-12.

https://doi.org/10.1080/09507116.2021.1906576 
[15] Siddique, Ahmed, Ghias, Vijaya, Ramnath., B. , \& Elanchezhian., C. , et al. (2019). Analysis of the friction welding mechanism of low carbon steel -stainless steel and aluminium - copper sciencedirect. Materials Today: Proceedings, 16(P2), 766-775.

https://doi.org/10.1016/j.matpr.2019.05.157

[16] Panaskar, N. , \& Terkar, R. P. . (2020). Optimization of friction stir welding process parameters for aa6063-etp copper using central composite design. World Journal of Engineering, ahead-of-print(ahead-of-print). https://doi.org/10.1108/WJE-11-2019-0322

[17] Hollatz, S. , Heinen, P. , Limpert, E. , Olowinsky, A. , \& Gillner, A. . (2020). Overlap joining of aluminium and copper using laser micro welding with spatial power modulation. Welding in the World, Le Soudage Dans Le Monde, 64(2). https://doi.org/10.1007/s40194-020-00848-9

[18] Rasch, M. , Roider, C. , Kohl, S. , Strauss, J. , Maurer, N. , \& Nagulin, K. Y. , et al. (2019). Shaped laser beam profiles for heat conduction welding of aluminium-copper alloys. Optics \& Lasers in Engineering, 115(APR.), 179-189. https://doi.org/10.1016/j.optlaseng.2018.11.025

[19] Yan, S. , \& Shi, Y. . (2019). Influence of laser power on microstructure and mechanical property of laser-welded al/cu dissimilar lap joints. Journal of Manufacturing Processes, 45(Sep.), 312-321.https://doi.org/10.1016/j.jmapro.2019.07.009

[20] Reisgen, U. , Olschok, S. , \& Holtum, N. . (2019). Influencing the electrical properties of laser beam vacuum-welded cu-al mixed joints. Journal of Laser Applications, 31(2):022406. https://doi.org/10.2351/1.5096093

[21] Dimatteo, V. , Ascari, A. , \& Fortunato, A. . (2019). Continuous laser welding with spatial beam oscillation of dissimilar thin sheet materials (al-cu and cu-al): process optimization and characterization. Journal of Manufacturing Processes, 44(AUG.),

158-165.https://doi.org/10.1016/j.jmapro.2019.06.002

[22] Weigl, M. , \& Schmidt, M. . (2009). Modulated laser spot welding of dissimilar copper-aluminium connections.

[23] Xu, C. , \& Peng, C. . (2020). Mechanical properties and microstructure analysis of welding brazing of al/ti butt joint with zn foil additive. Materials Research Express, 7(2), 026542 (11pp).https://doi.org/10.1088/2053-1591/ab5de5

[24] Katayama, S. . (2004). Laser welding of aluminium alloys and dissimilar metals. Welding International, 18(8), 618-625. https://doi.org/10.1533/wint.2004.3315

[25] Solchenbach, T. , \& Plapper, P. . (2013). Mechanical characteristics of laser braze-welded aluminium-copper connections. Optics \& Laser Technology, 54, 249-256.

https://doi.org/10.1016/j.optlastec.2013.06.003

[26] Xue, J. , Li, Y. , Hui, C. , \& Zhu, Z. . (2017). Effects of heat input on wettability, interface microstructure and properties of al/steel butt joint in laser-metal inert-gas hybrid welding brazing . Journal of Materials Processing Technology, 255, 47-54. 
[27] Cao, L. , Zhou, Q. , Liu, H. , Li, J. , \& Wang, S. . (2020). Mechanism investigation of the influence of the magnetic field on the molten pool behavior during laser welding of aluminum alloy. International Journal of Heat and Mass Transfer, 162, 120390.

https://doi.org/10.1016/j.ijheatmasstransfer.2020.120390

[28] Gatzen, M. , \& Tang, Z. . (2010). Cfd-based model for melt flow in laser beam welding of aluminium with coaxial magnetic field. Physics Procedia, 5(part-PB), 317-326.

https://doi.org/317-326.10.1016/j.phpro.2010.08.058\#

[29] Wu, C. , Yang, F. , \& Gao, J. . (2016). Effect of external magnetic field on weld pool flow conditions in high-speed gas metal arc welding. Proceedings of the Institution of Mechanical Engineers Part B Journal of Engineering Manufacture, 0954405414555591. https://doi.org/10.1177/0954405414555591

[30] Avilov, V. , Fritzsche, A. , Bachmann, M. , Gumenyuk, A. , \& Rethmeier, M. . (2015). Full penetration laser beam welding of thick duplex steel plates with electromagnetic weld pool support. Journal of Laser Applications, 28(2), 022420. https://doi.org/10.2351/1.4944103

[31] Cao, L., Yang, Y. , Jiang, P. , Zhou, Q. , Mi, G. , \& Gao, Z. , et al. (2017). Optimization of processing parameters of aisi-3161 laser welding influenced by external magnetic field combining rbfnn and ga. Results in Physics, 7, 1329-1338. https://doi.org/10.1016/j.rinp.2017.03.029

[32] Fan, L. , Zhong, Y. , Xu, Y. , Zhe, S. , \& Ren, Z. . (2015). Effect of static magnetic field on microstructure and interdiffusion behavior of fe/fe-si alloy diffusion couple. Journal of Alloys and Compounds, 645, 369-375. http://doi.org/10.1016/j.rinp.2017.03.029

[33] Bachmann, M. , Avilov, V. , Gumenyuk, A. , \& Rethmeier, M. . (2014). Experimental and numerical investigation of an electromagnetic weld pool support system for high power laser beam welding of austenitic stainless steel. Journal of Materials Processing Technology, 214(3), 578-591. https://doi.org/10.1016/j.jmatprotec.2013.11.013

[34] Wu, C. , Han, S. , Xue, D. , \& Zhan, J. . (2021). On the fluid behavior and stability of ti-6al-4v titanium alloy gmaw molten pool: effect of the longitudinal magnetic field. Modern Physics Letters B, 35(17), 2150283. https://doi.org/10.1142/S0217984921502833

[35] Esfahani, M. , Coupland, J. , \& Marimuthu, S. . (2015). Numerical simulation of alloy composition in dissimilar laser welding. Journal of Materials Processing Technology, 224, 135-142. https://doi.org/10.1016/j.jmatprotec.2015.05.005

[36] Thejasree, P. , Manikandan, N. , Binoj, J. S. , Varaprasad, K. C. , \& Raju, R. . (2020). Numerical simulation and experimental investigation on laser beam welding of inconel 625. Materials today: proceedings. https://doi.org/10.1016/j.matpr.2020.07.042

[37] Partes, K. , Schmidt, M. , \& Gorny, S. . (2020). Prediction of preheating temperatures for s690ql high strength steel using fem-simulation for high power laser welding. Lasers in 
Manufacturing and Materials Processing, 7(2), 177-189.

https://doi.org/10.1007/s40516-020-00111-5

[38] M Behúlová, E Babalová, \& Nagy, M. . (2017). Simulation model of Al-Ti dissimilar laser welding brazing and its experimental verification. Materials Science and Engineering Conference Series. https://doi.org/10.1088/1757-899X/179/1/012007

[39] Assael, M. J. , AE Kalyva, Antoniadis, K. D. , Banish, R. M. , Egry, I. , \& Wu, J. , et al. (2010). Reference data for the density and viscosity of liquid copper and liquid tin. Journal of Physical \& Chemical Reference Data, 39(3), 285. https://doi.org/10.1063/1.3467496

[40] Phanikumar, G. , Chattopadhyay, K. , \& Dutta, P. . (2004). Computational modeling of laser welding of cu-ni dissimilar couple. Metallurgical \& Materials Transactions B, 35(2), 339-350.

https://doi.org/10.1007/s11663-004-0034-4

[41] Webb, E. B. , \& Grest, G. S. . (2001). Liquid/vapor surface tension of metals: embedded atom method with charge gradient corrections. Physical Review Letters, 86(10), 2066-2069.

https://doi.org/10.1103/PhysRevLett.86.2066 